https://doi.org/10.15407/ujpe65.10.875

M.D. GLINCHUK, ${ }^{1}$ L.P. YURCHENKO ${ }^{1}$ V.V. LAGUTA ${ }^{1,2}$

${ }^{1}$ Institute for Problems of Materials Science, Nat. Acad. of Sci. of Ukraine

(3, Krjijanovskogo Str., Kyiv 03680,Ukraine; e-mail: glin@ipms.kiev.ua)

2 Institute of Physics AS CR

(Na Slovance 2, 182 21, Prague 8, Czech Republic)

\title{
GIANT MAGNETOELECTRIC RESPONSE IN MULTIFERROICS WITH COEXISTENCE OF SUPERPARAMAGNETIC AND FERROELECTRIC PHASES AT ROOM TEMPERATURE
}

\begin{abstract}
Multiferroics are materials having two or more order parameters (for instance, magnetic, electric, or elastic) coexisting in the same phase. They have emerged as an important topic in condensed matter physics due to both their intriguing physical behaviors and a broad variety of novel physical applications they enable. Here, we report the results of comprehensive studies of the magnetoelectric (ME) effect in multiferroics with superparamagnetic and ferroelectric phases. On the example of a solid solution of $\mathrm{PbFe}_{1 / 2} \mathrm{Ta}_{1 / 2} \mathrm{O}_{3}$ with $\left(\mathrm{PbMg}_{1 / 3} \mathrm{Nb}_{2 / 3} \mathrm{O}_{3}\right)_{0.7}\left(\mathrm{PbTiO}_{3}\right)_{0.3}$ or $\mathrm{Pb}(\mathrm{ZrTi}) \mathrm{O}_{3}$, we demonstrate that, in the system with the coexistent superparamagnetic and ferroelectric phases, the $M E$ coefficient can be increased up to three orders in magnitude as compared to conventional magnetoelectrics. This is supported by both theoretical calculations and direct measurements of the ME coefficient. Our study demonstrates that multiferroics with superparamagnetic and ferroelectric phases can be considered as promising materials for applications along with composite multiphase (ferroelectric/ferromagnetic) structures.
\end{abstract}

Ke ywords: multiferroics, magnetoelectrics effect, ferroelectrics, superparamagnetism, solid solutions.

\section{Introduction}

In the last years, the considerable attention of scientists and engineers was paid to multiferroics with strong magnetoelectric (ME) response at room temperature. It is because of the emergence of important physical topics in condensed matter physics and a lot of novel technical applications. In particular, the coupling of the electric polarization and magnetization in magnetoelectric materials is very promising for spintronic and magnetic random access memory applications. Nowadays, one of the most developed fields of practical applications is magnetic field sensors with sensitivity much larger than was known earlier, which opens the way for applications in medicine (see, e.g., [1]). It is obvious that, for the success of applications, the production of materials with maximal ME response at room temperature is the main condition.

(C) M.D. GLINCHUK, L.P. YURCHENKO, V.V. LAGUTA, 2020

ISSN 2071-0194. Ukr. J. Phys. 2020. Vol. 65, No. 10
Recently, the results obtained by us with other coauthors had shown [2] that this condition can be fulfilled in multiferroics in which the superparamagnetic and ferroelectric phases coexist. The detailed experimental and theoretical investigations of the ceramic solid solutions $\mathrm{PbFe}_{1 / 2} \mathrm{Ta}_{1 / 2} \mathrm{O}_{3}$ with

$\left(\mathrm{PbMg}_{1 / 3} \mathrm{Nb}_{2 / 3} \mathrm{O}_{3}\right)_{0.7}\left(\mathrm{PbTiO}_{3}\right)_{0.3}$

$\left[(\mathrm{PFT})_{x}\left(\mathrm{PMN}_{0.7} \mathrm{PT}_{0.3}\right)_{1-x}\right]$

had shown that this single-phase multiferroic with ferroelectric and superparamagnetic phases has a nonlinear paramagnetoelectric ME response three thousands times larger than that in broadest known earlier magnetoelectric materials. The main difficulty of obtained earlier results seems to be the very complex structure of the investigated multiferroic. In this paper, we will discuss the mechanism of such dramatic increase of the ME coefficient in detail. The aim of such approach is to find out the possible group of other materials with the coexistence of superparamagnetic and ferroelectric phases at room temperature. 


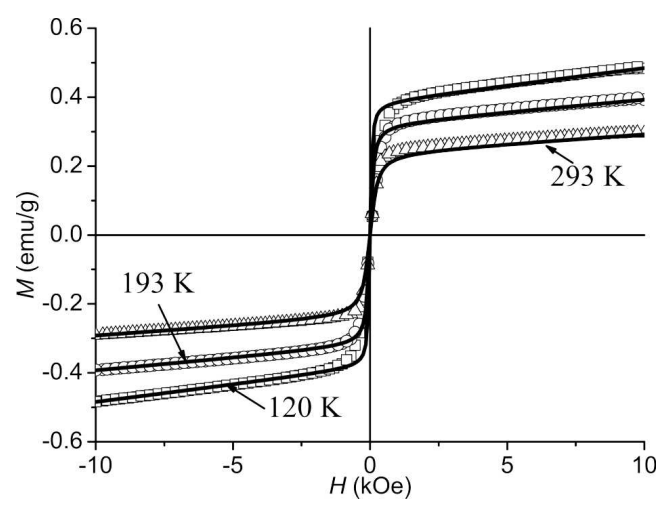

Fig. 1. Dependence of the magnetization on the magnetic field for a solid solution (PFT) $)_{x}(\mathrm{PMN}-\mathrm{PT})_{1-x}$ for $x=0.4$ at $T=120 \mathrm{~K}$ (open squares), $193 \mathrm{~K}$ (open circles), and $293 \mathrm{~K}$ (open triangles) [2]

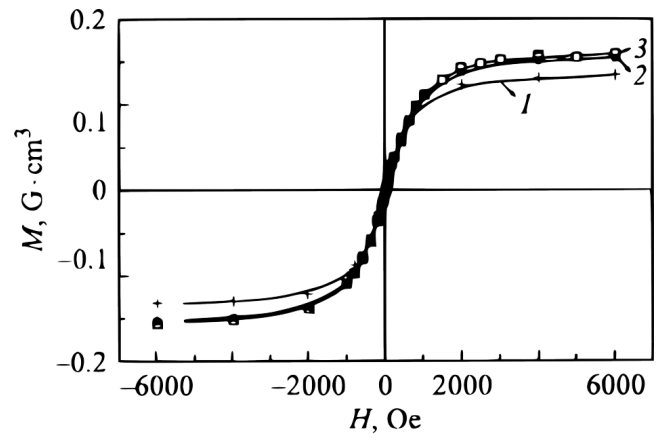

Fig. 2. Magnetic properties of a powder sample of nanoporous carbon filled by nickel particles: different curves are measured at temperatures 50 (1), 150 (2), and $300 \mathrm{~K}$ (3) [4]

Since we are going to pay attention mainly to magnetic and magnetoelectric properties of $(\mathrm{PFT})_{x}\left(\mathrm{PMN}_{0.7} \mathrm{PT}_{0.3}\right)_{1-x}$, we recommend the readers to find technological details of the preparation of samples and the investigation of their structure in [2]. In particular, X-ray data had shown that the ceramic micrograins consist of nanoscale structural units. The investigation of the dielectric and magnetic properties was performed for solid solutions with $x=0.4$ and 0.5 . Both components were shown to be ferroelectrics with diffuse phase transition. The distribution of iron ions in the investigated complex multiferroic was studied by the ${ }^{207} \mathrm{~Pb} \mathrm{NMR}$. It was possible due to a strong coupling of lead nuclear spins with iron electron spins.

\section{Superparamagnetic Phases}

The phenomenon of superparamagnetism, which appears in the ensemble of non-interacting ferromag- netic nanoparticles, is one of the most interesting and broadly investigated physical effects. It is related to the fact that, for the nanoparticles with radius smaller than the magnetic exchange length, all the spins are oriented coherently, and a barrier between different magnetization orientations is proportional to the nanoparticle volume and is small. As a result, the entire particle can be considered as a freely reorientable large spin up to some blocking temperature $T_{b}$ smaller than the barrier height. Contrary to the case of paramagnetic molecules, the superparamagnetic magnetization can be described, similarly to classical paramagnets, by the Langevin function, where the moment of the entire particle (rather than the moment of a single ion) has to be considered as an elementary moment.

Superparamagnetism has been observed not only in the powders of magnetic nanoparticles, but also in the nanocomposites on particles submerged into a polymeric matrix [3] or those located in the nanopores of non-magnetic materials [4]. It was shown recently [2] that the superparamagnetic phase can be obtain also in a single-phase ceramics like $(\mathrm{PFT})_{x}\left(\mathrm{PMN}_{0.7} \mathrm{PT}_{0.3}\right)_{1-x}(x=0.5,0.4)$, in which $\mathrm{X}$ ray data indicate that the ceramic micro-grains consist of nanosize structural units. The superparamagnetic behavior of the magnetization in an external magnetic field for the above-mentioned single phase ceramics and for the nanocomposite on the base of a powder sample of nanoporous carbon filled by Ni particles can be seen in Figs. 1 and 2, respectively. The main peculiarity is a strong increase of the magnetization in a low-strength magnetic field and a practically linear increase of the magnetization at high-strength magnetic fields. The solid lines in Figs. 1 and 2 show the fits of $M(H)$ curves by the sum of the paramagnetic and superparamagnetic contributions:

$M(H, T)=M_{s}+M_{p}$

$M_{s}(H, T)=N_{s} \mu_{s}(T) L\left[\frac{\mu_{s}(T) H}{k_{\mathrm{B}} T}\right]$,

where $N_{s}$ is the number of nano-sized grains or nanopores filled by $N_{i}$ nanoparticles; $\mu_{s}$ is the magnetic moment of a nanoparticle; $L(x)$ is the Langevin function $L(x) \equiv \operatorname{coth}(x)-1 / x$.

The parameters of a fitting in the case of multiferroic $(\mathrm{PFT})_{x}\left(\mathrm{PMN}_{0.7} \mathrm{PT}_{0.3}\right)_{1-x}$ are given in [2]. In what follows, we will pay the most attention namely 
to this material because of the coexistence of electric polarization and magnetization necessary for the magnetoelectric effect in it, whereas there is only the magnetization in nanocomposites on the base of carbon particles.

\section{Magnetoelectric Coupling in PFT-(PMN-PT)}

To throw light on the physical mechanism of a possible large magnetoelectric effect in multiferroics with the coexistence of superparamagnetism and ferroelectricity we will follow the results obtained in [2]. Within the phenomenological Landau-GinzburgDevonshire (LGD) approach, the contributions of the linear and biquadratic ME couplings to the free energy of the system are described by the terms $\mu_{i j} P_{i} M_{j}$ and $\xi_{i j k l} P_{i} P_{j} M_{k} M_{l}$, respectively ( $P_{i}$ is the polarization component and $M_{j}$ is the magnetization one, and $\mu_{i j}$ and $\xi_{i j k l}$ are corresponding tensors of linear and biquadratic ME couplings, respectively) [57]. Recently, the attention of scientists and engineers was also attracted to the paramagnetoelectric (PME) effect introduced by S. Hou and N. Blombergen [8]. It is described by the term $\lambda_{i j k} P_{i} M_{j} M_{k}$. Note that the elements of the tensors are averaged over a ceramics. Sometimes for simplicity, we will use the scalar LGD equations.

The linear and biquadratic ME coupling coefficients can be found by measuring the dependence of a magnetization on the external electric field (see, e.g., [6] and references therein). The paramagnetoelectric response can be measured via a PME current by the dynamic method. This current originated from the polarization $P_{a c}$ induced by a low magnetic field $h_{a c}$ under the application of a $d c$ field $H_{d c}[8,9]$. The magnetic-field-induced polarization can be obtained from the general form of the free energy $F(E, H)$ expansion $[10,11]$ :

$P_{i}=-\frac{\partial F}{\partial E_{i}}=P_{i}^{s}+\varepsilon_{0} \varepsilon_{i j} E_{j}+\alpha_{i j} H_{j}+\frac{1}{2} \beta_{i j k} H_{j} H_{k}$.

For collinear $d c$ and $a c$ magnetic fields $H=H_{d c}+$ $+h_{a c} \sin \omega t$, the first harmonic of the $a c$ polarization detected by a lock-in detector is

$P_{a c}(T)=\beta(T) H_{d c} h_{a c}$.
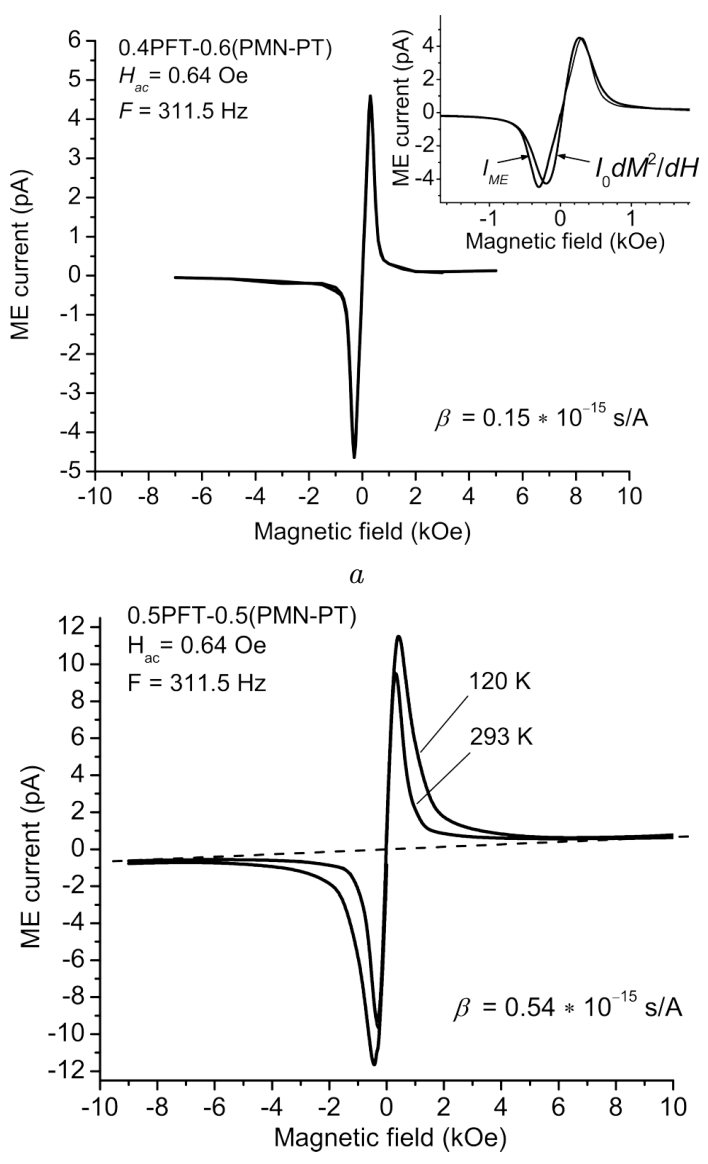

Fig. 3. ME current amplitude in $(\mathrm{PFT})_{x}(\mathrm{PMN}-\mathrm{PT})_{1-x}$ as a function of the applied $d c$ magnetic field for $x=0.4$ measured at $293 \mathrm{~K}(a)$ and $x=0.5$ measured at $293 \mathrm{~K}$ and $120 \mathrm{~K}(b)$. The dashed line in (b) shows a "linear" part of the ME current from the paramagnetic component. Insert: ME current amplitude for $x=0.4$ superimposed with $d M^{2} / d H$ calculated from the data of Fig. 1

The PME current across a sample with cross-section $\sigma$ is determined as

$I_{\mathrm{ME}}=\frac{d}{d t}\left(\beta \sigma H_{d c} h_{a c} \sin \omega t\right)=\beta \omega \sigma H_{d c} h_{a c} \cos \omega t$,

where $\omega$ is the measurement frequency.

Figure 3 shows the ME current as a function of the applied $d c$ magnetic field in $(\mathrm{PFT})_{x}\left(\mathrm{PMN}_{0.7} \mathrm{PT}_{0.3}\right)_{1-x}$ ceramics for two compositions $x=0.4$ and 0.5 . One can see that, in both samples, the ME signal sharply increases with the dc magnetic field in the interval \pm 300 Oe. Then it saturates in value and decreases down to almost zero at the fields larger than \pm 3000 Oe. 


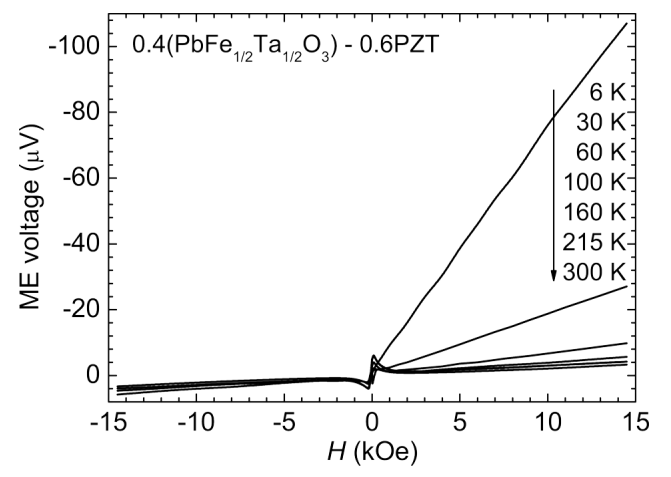

Fig. 4. ME voltage as a function of the applied bias magnetic field measured for $0.4 \mathrm{PFT}-0.6 \mathrm{PZT}$ ceramics at temperatures from $300 \mathrm{~K}$ down to $6 \mathrm{~K}$

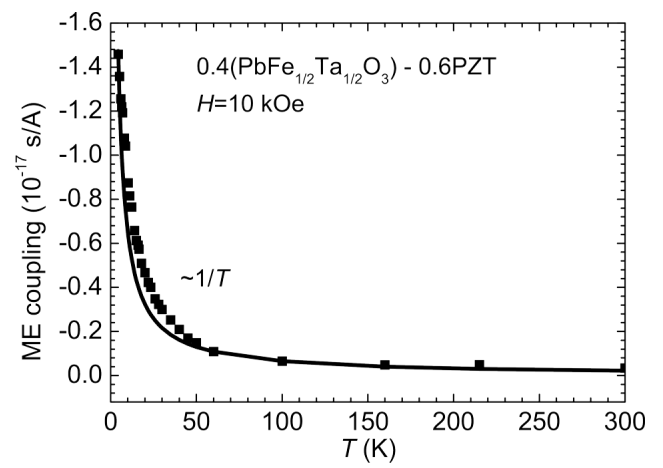

Fig. 5. Temperature dependence of the PME coupling coefficient of $0.4 \mathrm{PFT}-0.6 \mathrm{PZT}$ ceramics at the bias magnetic field of $10 \mathrm{kOe}$. Square symbols and the smooth line are measured and calculated data, respectively

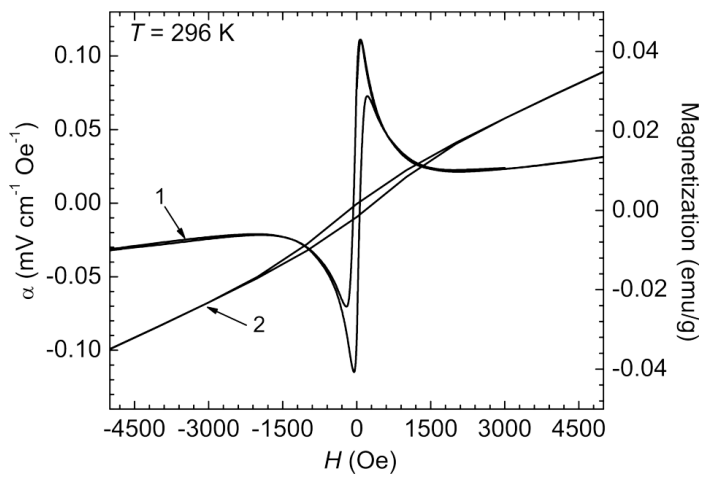

Fig. 6. Field dependence of the linear ME coefficient (1) and magnetization (2) measured for $0.4 \mathrm{PFT}-0.6 \mathrm{PZT}$ ceramics at $296 \mathrm{~K}$

To understand the physical mechanism of a strong increase of the ME current for small enough magnetic fields, let us consider, in more details, the contribution of a magnetoelectric coupling into the free en- ergy and into $P_{a c}$. In the actual case of the symmetric paraelectric-paramagnetic phase, we should retain a biquadratic ME coupling, which has the form

$F_{\mathrm{ME}}=\frac{\xi_{\mathrm{MP}}}{2}\left(M_{s}+\chi_{M} H\right)^{2}\left(P_{s}+\varepsilon_{0} \chi_{E} E\right)^{2}$,

where $P_{s}$ and $M_{s}$ are the spontaneous polarization and magnetization; and $\chi_{E, M}$ are the dielectric and magnetic susceptibilities.

Equation (6) leads to the following expression for $\beta=-\partial^{3} F_{\mathrm{ME}} /\left[(\partial E)^{2} \partial H\right]$ :

$\beta=\xi_{\mathrm{MP}} 2 P_{s}(T) \varepsilon_{0} \chi_{E}(T)\left[\chi_{M}(T)\right]^{2}$.

On the other hand, it is easy to see that Eq. (6) gives the polarization $P=-\partial F / \partial E$ in the form

$P=P_{P}+\Delta P_{\mathrm{ME}}$

$\Delta P_{\mathrm{ME}}=-\xi_{\mathrm{MP}} P_{s} \varepsilon_{0} \chi_{E}[M(H)]^{2}$.

In the experimental situation with collinear $d c$ and $a c$ magnetic fields, we obtain a generalization of Eq. (4) in the form:

$\Delta P_{\mathrm{ME}}=-\xi_{\mathrm{MP}} P_{s} \varepsilon_{0} \chi_{E}\left[M\left(H_{0}\right)^{2}+\right.$

$\left.+\left.2 M\left(H_{0}\right) \frac{\partial M(H)}{\partial H}\right|_{H=H_{0}} h_{0} \sin \omega t\right]$.

One can see that

$P_{a c}=-\left.\xi_{\mathrm{MP}} P_{s} \varepsilon_{0} \chi_{E} 2 M\left(H_{0}\right) \frac{\partial M(H)}{\partial H}\right|_{H=H_{0}} h_{0} \sin \omega t$.

Hence, the generalization of Eq. (5) shows that the amplitude of the magnetoelectric current $I_{\mathrm{ME}}$ is proportional to $d M^{2} / d H$ (see the insert in Fig. 3, $a$ ). Therefore, $I_{\mathrm{ME}}$ is proportional to $d M^{2} / d H$, as shown in the insert in Fig. 3, $a$, i.e., calculated on the base of Fig. 1 for the superparamagnetic phase magnetization.

\section{Magnetoelectric Coupling in 0.4PFT-0.6PZT Ceramics}

Another example of ME materials, where the ME coupling is quite large, is the solid solution of PFT with $\mathrm{Pb}(\mathrm{ZrTi}) \mathrm{O}_{3}(\mathrm{PZT})$. In particular, the composition 0.4PFT-0.6PZT was studied. Figure 4 shows the dependence of the ME voltage as a function of the bias magnetic field at temperatures from $300 \mathrm{~K}$ down to $6 \mathrm{~K}$. One can see that the behavior of the ME response in a magnetic field at $T>100 \mathrm{~K}$ is very similar to that of $0.4 \mathrm{PFT}-0.6(\mathrm{PMN}-\mathrm{PT})$ ceramics presented in Fig. 3. Namely, there are a strongly nonlinear ME

ISSN 2071-0194. Ukr. J. Phys. 2020. Vol. 65, No. 10 
response in small magnetic fields and the linear part at $H> \pm 1 \mathrm{kOe}$. This linear part of the ME signal is related to the paramagnetoelectric contribution to the ME signal. The paramagnetoelectric contribution strongly increases, as the temperature decreases. Its temperature dependence (calculated ME coupling coefficient) measured at a magnetic field of $10 \mathrm{kOe}$ is shown in Fig. 5. It follows well the temperature dependence of the magnetic susceptibility (or its square) in the paramagnetic phase created by isolated $\mathrm{Fe}^{3+}$ ions. The ME coefficient in this phase goes to infinity, as the temperature approaches $0 \mathrm{~K}$ due to the relation $\chi \sim 1 / T$. However, its actual value is, of course, limited by the saturated magnetization of spins in a magnetic field.

Another part of the ME signal is related to superparamagnetism or rather weak magnetism of $0.4 \mathrm{PFT}$ 0.6PZT ceramics. Figure 6 shows this ME signal at low magnetic fields together with the magnetization. The magnetization nonlinearly changes at $H< \pm 2 \mathrm{kOe}$ and shows a hysteresis with slim magnetization loop and the remanent magnetization $\approx 0.004 \mathrm{emu} / \mathrm{g}$. A similar hysteresis is seen in the ME signal. Obviously, the superparamagnetic clusters in $0.4 \mathrm{PFT}-0.6 \mathrm{PZT}$ ceramics are larger in volume than those in 0.4PFT-0.6(PMN-PT), and some interaction may also exist between them. This leads to the freezing (thermal blocking) of the superparamagnetic moments of clusters [12] even at room temperature. Because the remanent magnetization is non-zero, the linear ME effect is expected. Namely, the bias field dependence of the linear ME coefficient in the technical units [1] is shown in Fig. 6. Note that similar magnetic loops were observed for PFN-PZT and PFTPZT ceramics in [13]. However, the remanent magnetization ascribed to ferromagnetism was few times higher than that in our ceramics. The much larger difference was in the measured ME coefficient: the ME voltage coefficient $\alpha \approx 12 \mathrm{mV} / \mathrm{cm}$. Oe was reported for $0.2 \mathrm{PFT}-0.8 \mathrm{PZT}$ composition, which only slightly changed with a bias field in contrast to our measurements, where it strongly depends on the field value.

\section{Discussion and Conclusion}

Allowing for the generality of calculations presented in the previous section, the results obtained in [2] are valid for other multiferroics with superparamagnetic and ferroelectric phases. Because of this, let us discuss, in more details, the ME effect in a PFT-PMN-PT solid solution. It would be of interest to compare the measured PME coefficients with those obtained by the same method for other multiferroics. The authors of Refs. [11, 14] investigated the solid solution $\left(\mathrm{PbFe}_{1 / 2} \mathrm{Nb}_{1 / 2} \mathrm{O}_{3}\right)_{x}\left(\mathrm{PbTiO}_{3}\right)_{1-x}$ (PFN-PT). The structure, properties, and phase diagram of PFN are similar to those of PFT. However, the properties of the second components of solid solutions, namely $(\mathrm{PMN})_{0.7}(\mathrm{PT})_{0.3}$ and PT [11], are completely different. One can suppose that the difference in the ME effects is mainly induced by the second component of the solid solution. The ME coefficient measured in [2] at room temperature is equal to $\beta \approx$ $0.54 \times 10^{-15} \mathrm{~s} / \mathrm{A}(x=0.5)$, while that the coefficient obtained for PFN-PT [11, 14] appeared to be much smaller, $\beta \sim 10^{-18} \mathrm{~s} / \mathrm{A}$. The superpaparamagnetic contribution is not even visible in magnetic measurements for PFN-PT (see Fig. 1, $d$ of Ref. [11]). The obtained values of the PME coefficient in PFT-PMNPT appeared to be also much larger than that determined in several other antiferromagnetic multiferroic materials (see Table I in Ref. [14]): $\mathrm{BiFeO}_{3}$ $\left(2.1 \times 10^{-19} \mathrm{~s} / \mathrm{A}\right), \mathrm{Gd}_{2}\left(\mathrm{MoO}_{4}\right)_{3}\left(0.8 \times 10^{-18} \mathrm{~s} / \mathrm{A}\right)$ and $\mathrm{NiSO}_{4} \cdot 6 \mathrm{H}_{2} \mathrm{O}\left(0.7 \times 10^{-18} \mathrm{~s} / \mathrm{A}\right)$. Note that the strong scattering of $\mathrm{ME}$ effect values in PFT-PZT solid solutions (see, e.g., $[5,13,15,16]$ made it cumbersome to perform a direct comparison with our results obtained for a PFT-PMN-PT solid solution.

The studies performed by us demonstrate that the multiferroics with superparamagnetic and ferroelectric phases can be considered as promising materials for applications along with composite multiphase (ferroelectric/ferromagnetic) layered structures [1, 10]. Since the ME response in multiferroics with the superparamagnetic phase is proportional to $d M^{2} / d H$, its value can be amplified by many orders due to a sharp change of the magnetization with a field.

The discovery of the physical mechanism responsible for the giant ME response opens the way of obtaining the novel single-phase or multiphase multiferroics necessary for devices of modern electronics. In particular, the superparamagnetic magnetization of the composite based on a carbon powder with nanopores filled by $\mathrm{Ni}$ (see Fig. 2) might be obtained, to our mind, by using some ferroelectric materials (e.g., $\mathrm{KNbO}_{3}$ with a large region of the $\mathrm{FE}$ phase) instead of carbon. On the other hand, in a singlephase multiferroic on the base of nano-sized particles 
of $\mathrm{Fe}_{3} \mathrm{O}_{4}$ with the superparamagnetic phase (see, e.g., [17]) the ferroelectric phase can be induced by the annealing in the nitrogen atmosphere, producing oxygen vacancies, which can introduce the $\mathrm{FE}$ phase due to the Vegard effect.

This work was supported in part by the Research Executive Agency (grant agreement 778072 ENGIMA - H2020-MSCA-RISE-2017).

1. A.P. Pyatakov, A.K. Zvezdin. Magnetoelectric and multiferroic media. Physics - Uspekhi 55, 557 (2012).

2. M.D. Glinchuk, R.O. Kuzian, Yu.O. Zagorodniy, I.V. Kondakova, V.M. Pavlikov, M.V. Karpec, M.M. Kulik, S.D. Skapin, L.P. Yurchenko, V.V. Laguta. Room-temperature ferroelectricity, superparamagnetism and large magnetoelectricity of solid solution $\mathrm{PbFe}_{1 / 2} \mathrm{Ta}_{1 / 2} \mathrm{O}_{3}$ with $\left(\mathrm{PbMg}_{1 / 3} \mathrm{Nb}_{2 / 3} \mathrm{O}_{3}\right)_{0.7}\left(\mathrm{PbTiO}_{3}\right)_{0.3}$. J. Mat. Sci. 55, 1399 (2020).

3. F. Wiekhorst, E. Shevchenko, H. Weller, J. Kotzler. Anisotropic superparamagnetism of monodispersive cobalt-platinum nanocrystals. Phys. Rev. B 67, 224416 (2003).

4. V.M. Fedosyuk, A.M. Danishevskiframe, D.A. Kurdyukov, V.B. Shuman, S.K. Gordeev. Magnetic properties of nickel clusters in nanoporous carbon. Physica of Solid State 45, 9, 1750 (2003).

5. D.A. Sanchez, N. Ortega, A. Kumar, R. Roque-Malherbe, R. Polanco, J.F. Scott, R.S. Katiyar. Symmetries and multiferroic properties of novel room-temperature magnetoelectrics: Lead iron tantalate-lead zirconate titanate (PFT/PZT). AIP Advances 1, 042169 (2011).

6. M.D. Glinchuk, E.A. Eliseev, A.N. Morozovska. Landau-Ginzburg description of anomalous properties of novel room temperature multiferroics $\mathrm{Pb}\left(\mathrm{Fe}_{1 / 2} \mathrm{Ta}_{1 / 2}\right)_{x}\left(\mathrm{Zr}_{0.53} \mathrm{Ti}_{0.47}\right)_{1-x} \mathrm{O}_{3} \quad$ and $\mathrm{Pb}\left(\mathrm{Fe}_{1 / 2} \mathrm{Nb}_{1 / 2}\right)_{x}\left(\mathrm{Zr}_{0.53} \mathrm{Ti}_{0.47}\right)_{1-x} \mathrm{O}_{3}$. J. Appl. Phys. 119, 024102 (2016).

7. M.D. Glinchuk, E.A. Eliseev, A.N. Morozovska, R. Blinc. Giant magnetic effect induced by intrinsic surface stress in ferroic nanorods. Phys. Rev. B 77, 024106 (2008).

8. S.L. Hou, N. Bloembergen. Paramagnetoelectric effects in $\mathrm{NiSO}_{4} \cdot 6 \mathrm{H}_{2} \mathrm{O}$. Phys. Rev. 138, A1218 (1965).

9. T. Watanabe, K. Kohn. Magnetoelectric effect and low temperature transition of $\mathrm{PbFe}_{0.5} \mathrm{Nb}_{0.5} \mathrm{O}_{3}$ single crystal. Phase Transitions 15, 57 (1989).

10. M. Fiebig. Revival of the magnetoelectric effect. J. Phys. D: Appl. Phys. 38, R123 (2005).

11. V.V. Laguta, A.N. Morozovska, E.A. Eliseev, I.P. Raevski, S.I. Raevskaya, E.I. Sitalo, S.A. Prosandeev, L. Bellaiche. Room-temperature paramagnetoelectric effect in magnetoelectric multiferroics $\mathrm{Pb}\left(\mathrm{Fe}_{1 / 2} \mathrm{Nb}_{1 / 2}\right) \mathrm{O}_{3}$ and its solid solution with $\mathrm{PbTiO}_{3}$. J. Mat. Sci. 51, 5330 (2016).

12. C.M. Hurd. Varieties of magnetic order in solids. Contemporary Physics 23, 469 (1982).
13. D.A. Sanchez, N. Ortega, A. Kumar, G. Sreenivasulu, R.S. Katiyar, J.F. Scott, D.M. Evans, M. Arredondo-Arechavala, A. Schilling, J.M. Gregg. Roomtemperature single phase multiferroic magnetoelectrics: $\mathrm{Pb}(\mathrm{Fe}, \mathrm{M})_{x}(\mathrm{Zr}, \mathrm{Ti})_{(1-x)} \mathrm{O}_{3}[\mathrm{M}=\mathrm{Ta}, \mathrm{Nb}]$. J Appl. Phys. 113, 074105 (2013).

14. V.V. Laguta, V.A. Stephanovich, I.P. Raevski, S.I. Raevskaya, V.V. Titov, V.G. Smotrakov, V.V. Eremkin. Magnetoelectric effect in antiferromagnetic multiferroic $\mathrm{Pb}\left(\mathrm{Fe}_{1 / 2} \mathrm{Nb}_{1 / 2}\right) \mathrm{O}_{3}$ and its solid solutions with $\mathrm{PbTiO}_{3}$. Phys. Rev. B 95, 014207 (2017).

15. D.M. Evans, A. Schilling, A. Kumar, D. Sanchez, N. Ortega, M. Arredondo, R.S. Katiyar, J.M. Gregg, J.F. Scott. Magnetic switching of ferroelectric domains at room temperature in multiferroic PZTFT. Nature Communications 4, 1534 (2013).

16. D.M. Evans, A. Schilling, A. Kumar, D. Sanchez, N. Ortega, R.S. Katiyar, J.F. Scott, J.M. Gregg. Switching ferroelectric domain configurations using both electric and magnetic fields in $\mathrm{Pb}(\mathrm{Zr}, \mathrm{Ti}) \mathrm{O}_{3}-\mathrm{Pb}(\mathrm{Fe}, \mathrm{Ta}) \mathrm{O}_{3}$ single-crystal lamellae. Phil. Trans. R. Soc. A 372, 20120450 (2014).

17. J.A. Lopez-Perez, M.A. Lopez Quintela, J. Mira, J. Rivas, S.W. Charles. Advances in the preparation of magnetic nanoparticles by the microemulsion method. J. Phys. Chem. B 101, 8045 (1997).

Received 09.07.20

М.Д. Глинчук, Л.П. Юрченко, В.В. Лагута

ГІГАНТСЬКИЙ МАГНІТОЕЛЕКТРИЧНИЙ

ВІДГУК У МУЛЬТИФЕРӦ̈КАХ ІЗ СПІВІСНУВАННЯМ СУПЕРПАРАМАГНІТНОЇ ТА СЕГНЕТОЕЛЕКТРИЧНОЇ ФАЗ ПРИ КІМНАТНІЙ ТЕМПЕРАТУРІ

$\mathrm{P}$ е $з$ ю м е

Мультифероїки - це матеріали, що мають два або більше параметрів порядку (наприклад, магнітний, електричний або пружний), які співіснують в одній і тій самій фазі. Вони стали важливою задачею фізики конденсованих речовин завдяки їх незвичайним фізичним властивостям та широкому розмаїттю нових фізичних застосувань, які вони відкривають. Тут ми представляємо результати комплексного дослідження магнітоелектричного (ME) ефекту у мультифероїках із суперпарамагнітною та сегнетоелектричною фазами. На прикладі твердого розчину $\mathrm{PbFe}_{1 / 2} \mathrm{Ta}_{1 / 2} \mathrm{O}_{3}$ $3\left(\mathrm{PbMg}_{1 / 3} \mathrm{Nb}_{2 / 3} \mathrm{O}_{3}\right)_{0.7}\left(\mathrm{PbTiO}_{3}\right)_{0.3}$ або $\mathrm{Pb}(\mathrm{ZrTi}) \mathrm{O}_{3}$ ми демонструємо, що в системі зі співіснуючими суперпарамагнітними і сегнетоелектричними фазами МЕ коефіцієнт може бути більшим на три порядки, ніж у звичайних магнітоелектриків. Це підтверджується як теоретичними розрахунками, так і прямими вимірюваннями МЕ коефіцієнта. Наше дослідження демонструє, що мультифероїки із суперпарамагнітною та сегнетоелектричною фазами можуть розглядатися як перспективні матеріали для застосування поряд із композиційними багатофазними (сегнетоелектричними/феромагнітними) структурами. 